\title{
Putting Skills to Work: It's not so much the What, or even the Why, but
}

\section{How...}

\author{
Trisha Fettes, Karen Evans and Elnaz Kashefpakdel
}

\section{Introduction - the problem}

Young people as a group are four times more likely to be unemployed than older groups, many struggling with the transition between education and employment. Employers regularly voice concerns over lack of work-readiness and young people themselves [say] that the gaps between education and employment are daunting.

Youth Employment June 2017: 2

There are widespread beliefs that young people are struggling to make their way in life as education system and labour market changes have combined to create a world of unprecedented challenges. These challenges have intensified despite increases in levels of qualifications and years of schooling (Kashefpakdel and Percy 2016; Mann et al. January 2017).

The labour market is rapidly changing in the face of new technological and data-driven demands and becoming more complex. Permanent work is being replaced with 'flexible work arrangements that threaten the revival of casualised labour markets' and there have been 'profound shifts in patterns of movement from education to employment, as the youth labour markets have reduced and direct transitions from school to a job have long since ceased to be the norm' (Purcell et al. September 2017:33).

Rather than being single, linear events, transitions can involve: 'u-turns, detours and zig-zag movements...such as returning to education or moving in and out of employment' (Schoon and Lyons-Amos 2016: 10). For many young adults, gaining a foothold in the labour market is a prolonged process often characterised by periods of 'economic inactivity

\footnotetext{
${ }^{+}$Title adapted from Evans, Guile and Harris (October 2008) Putting Knowledge to Work; and question posed by the UK Commission for Employment and Skills in The Employability Challenge, (February 2009)
} 
alternating with spells of work and job search' (Quintini, Martin and Martin January 2007: 4). 'There is more competition for entry level employment' and employers are 'increasingly seeking new employees who are 'well-placed to be personally effective in applying knowledge and skills in changing situations'(Mann and Huddleston 2016: 211).

In preparing young adults for work, there has been a long history of identifying skills, qualities, attitudes and behaviours required to be successful in the workplace. For example, almost three decades since the Confederation of British Industry published Towards a Skills Revolution: A Youth Charter (CBI 1989) which emphasised the importance of developing young people's employability skills.

Although variously labelled ${ }^{2}$ and no one definitive list, generic-type skills such as communication, problem solving and teamworking are commonly reported to be essential for both the UK's economy and individuals (e.g. Prince's Trust 2016; Taylor July 2015³), along with attributes such as 'resilience, enthusiasm and creativity' (CBI and Pearson July 2016: 31). For example, it is reported that 'soft skills are worth over $£ 88$ billion in Gross Added Value to the UK economy each year' and, by 2020 , 'expected to grow in real terms to $£ 109$ billion' (Development Economics January 2015: 8). It is claimed that these skills have a longer shelf-life than technical and practical skills, enabling employees to be better able to adapt to the changing nature of work, and transition between jobs.

Over the same period, there has been a stream of government initiatives and various programmes in compulsory and post-compulsory education that have sought to prepare young people for work. For example, OECD (as quoted in Universities UK August 2018) reports that

\footnotetext{
${ }^{2}$ For example: common, core, key, essential, soft and transferable skills. For the history and fuller discussion see Fettes. 2012

${ }^{3}$ Prince's Trust. 2016. Results for Life Report. Prince's Trust/HSBC (online survey of 2,224 11-19 year olds, 2,675 workers and 1,000 teachers); Taylor, M. July 2015. Good Work: The Taylor Review of Modern Working Practices. BEIS
} 
'over $90 \%$ of universities offer skills development services for the enhancement of communication, enterprise, self-awareness and team-working skills' (14). However, many employers (e.g. in surveys by: AGR; British Chambers of Commerce; EY Foundation; $\mathrm{UKCES}^{4}$ ) continue to suggest that they find it difficult to recruit young adults with the essential, non-technical workplace skills, the people and personal skills needed for entry-level jobs. In the Construction Industry, for example, the Industry Training Board (CITB, June 2015) has suggested that government skills policy needs to focus on 'increasing the supply of transferable skills' (5).

The inference is that education providers are not adequately preparing young people for work, not teaching them the skills needed in the labour market. But is this necessarily the case?

\section{Materials and Methods}

The paper draws on literature reviews and findings from a study supported by the Commercial Education Trust (CET) that aimed to explore practices in educational programmes which encourage employer engagement in skills development, with the intention of informing further, more in-depth research.

The research, conducted between December 2016 and November 2017, comprised three phases and adopted a mixed method, qualitative approach:

1. Literature review: to explore the role of generic skills in facilitating education-towork transitions and put the study into context. To update findings from the authors' previous research (e.g. Evans, 2008, 2009, 2010; Fettes 2012; Kashefpakdel 2016), the focus was primarily on literature published since 2015

\footnotetext{
${ }^{4}$ Association of Graduate Recruiters. 2017. AGR Development Survey 2017 (based on 174 employer responses from over 18 sectors with 18,227 graduate hires); British Chambers of Commerce. 2014. Workforce Survey 2014 (2,885 responses from UK businesses); Ernest Young Foundation. June 2017. A Framework for Success. Connecting Young People with Employers from School to Work (survey of 500 SMEs); UK Commission for Employment and Skills. May 2016. Employer Skills Survey 2015: UK Results. (over 91,000 interviews with UK employers).
} 
2. Fieldwork: to gather views and examples of practice from educationalists, employers and entrepreneurs, and young adults, on skills needed to access and perform well at work, and approaches used to develop them. This phase included:

- A workshop for organisations known to the study sponsor (CET), as having effective skills development practice. Staff from 5 organisations who volunteered to contribute were asked during small group discussions to identify and then share with the whole group: a) skills developed through participants' respective programmes; b) learning environments, teaching and learning methods and employer engagement activities that support the development and utilisation of skills. Discussion points were recorded

- Two sets of semi-structured, recorded telephone interviews with 5 workshop participants, plus 3 telephone interviews with staff from one other organisation to explore further examples of practice and individual stories

- Three meetings with a business advisory group established by CET to provide business perspectives on the study's emerging findings and examples of workplace practice. The ten members included those with experience of entrepreneurship and/or working in large corporations, or Small \& Medium Enterprises (SMEs), across a range of occupational sectors, including Finance, Construction, Creative, Engineering and Information and Communications Technologies. Interviews with 3 members were also recorded ( 2 telephone; one face-to-face) to explore further issues raised in the meetings

- Online survey to follow-up graduates from three case study organisations (CS1, CS5, CS6) that volunteered to email the survey link to 573 leavers who were thought be in the workplace to find out the extent to which they perceived generic skills to be important. Respondents were invited to select from dropdown menus their level of preparedness for work; knowledge, skills and qualities felt to be important in a) being prepared for work and b) performing well at work. Open-response questions requested examples of difficulties faced in moving into work, skills they were using and how they were being used.

3. Analysis and reporting: A framework developed by Evans, Guile and Harris (2008, 2009), informed by extensive fieldwork and the work of Bernstein, Barnett and van Oers', was used in organising data for analysis and reporting in relation to: content recontexualisation (programme design), pedagogical recontextualisation (teaching and learning) and workplace environments that support learners in recontextualising skills learnt in one context to suit new and different contexts. This framework was combined with features of "powerful learning environments", a model used by de Bruijn and Leeman (2011) 'which is 'grounded in the idea of cognitive apprenticeship (Collins, Brown, and Newman, 1989)' and 'inspired by sociocultural theory'(695).

Case studies were developed through the interviews with programme staff to illustrate current practice (see Table 1 below). 
Table 1: Case Studies

\begin{tabular}{|c|l|}
\hline Case Study & \multicolumn{1}{c|}{ Type of organisation/focus } \\
\hline CS1 & $\begin{array}{l}\text { Education Charity that supports academies in equipping school pupils to go on to } \\
\text { university or a career of their choice. Focus: skills development in the context of a } \\
\text { BTEC programme and bespoke work-readiness curriculum }\end{array}$ \\
\hline CS2 & $\begin{array}{l}\text { Not-for-profit social enterprise that works with schools to build essential skills } \\
\text { into the curriculum and develop partnerships with employers and other skills- } \\
\text { building organisations. Focus: skills development in the context of an Enterprise } \\
\text { programme }\end{array}$ \\
\hline CS3 & $\begin{array}{l}\text { Education Charity that helps State schools to connect with alumni who can act as } \\
\text { role models, provide insights into career paths and work, and enrich the core } \\
\text { curriculum and access to employers. Focus: skills development in the context of } \\
\text { subject lessons }\end{array}$ \\
\hline CS4 & $\begin{array}{l}\text { A Youth Charity that helps disadvantaged young people turn their lives around } \\
\text { and gain the skills and confidence needed to find a job or training opportunity or } \\
\text { set up their own business. Focus: skills development in the context of an } \\
\text { Enterprise programme }\end{array}$ \\
\hline CS5 & $\begin{array}{l}\text { An Academy that offers HE student scholarships to support the development of } \\
\text { leadership skills needed in the Engineering sector. Focus: skills development in } \\
\text { the context of student-led personal development }\end{array}$ \\
\hline CS6 & $\begin{array}{l}\text { Education Charity that runs HE student and employee events to develop skills } \\
\text { needed in the construction industries. Focus: skills development in the context of } \\
\text { extra-curricular team activities }\end{array}$ \\
\hline
\end{tabular}

\section{Results}

\section{Findings from the literature review}

Some literature suggests that to manage transitions successfully, individuals need to develop “career adaptability skill” (Koen, Ute-Christine Klehe and Van Vianen 2012): 'an attitude of curiosity to explore self and environment, and confidence to design [their] occupational future' (Ebenehi, Rashid and Bakar December 2016: 214); and 'readiness to cope with the predictable tasks of preparing for and participating in the work role and with unpredictable adjustments prompted by changes in work and working conditions' (Savickas 1997: 254). Those who have been 'unable to develop their potential and acquire marketable skills, can lack the confidence to identify and pursue opportunities and to present themselves to employers' (34), a problem exacerbated by a mismatch in understanding what is meant by being "work ready" (Purcell et al. September 2017: 12). 
For young people to feel 'better prepared for adult working life, both the quantity and quality of employer engagement matters' (Mann et al. January 2017: 5). For example, business partners can help individuals to develop "career adaptability skill” by enhancing their 'understanding of jobs and careers', providing 'authentic, relevant experiences and practical insights into how recruitment processes work, and contemporary workplaces operate', and enable learners to 'build complementary skills such as creative problem solving and team working’ (Mann, Rehill and Kashefpakdel January 2018: 70). ' ...iterative movement between classroom learning and being in work settings and spaces', can help to 'develop learners' capability to make appropriate judgements and to act appropriately in occupational practices...' (Bound et al. 2018: 113).

In the vocational literature described by Akkemann and Bakker (2012), there seems to be a move away from a comparative approach which tends to focus on transfer (154), towards a relational approach which rests on notions such as boundary crossing. Whereas the former approach is 'mostly about one-time and one-directional transitions, leading to questions about the correctness of the school curriculum... about whether students can recall and apply what they have learned in school', the latter is about 'establishing a productive relation between school and work... based on a shared interest in the development of future professionals' (155).

Developing strong connections with partners can 'enrich learning environments [and] extend boundaries, resources and learning spaces' (OECD 2013: 12). However, this 'creates multiple challenges to educators' (OECD as quoted in Universities UK August 2018: 10) and raises questions about how learning partners negotiate and communicate across school and work environments to support the development of skills.

Some literature goes further in suggesting there needs to be a new way of thinking about public policies that moves away from those that have 'disproportionately focused on 
increasing the supply of skills side' to more attention being given to 'shaping how skills are used in the workplace' (OECD 2017: 28), to supporting more effective "skills utilisation" (Warhurst and Findley. January 2012). People not only need to be 'well-matched to jobs [but] move into jobs that use their skills' (HM Treasury 2015: 41).

The problem may not always be lack of skills, but with skills not being fully articulated and recognised during recruitment processes, and then used effectively in the workplace. Informal recruitment methods such as word of mouth recommendations can 'disadvantage those without the necessary social connections and networks' (House of Lords Select Committee on Social Mobility April 2016: 6). For recruiters, an absence of significant work experience can lead to an underestimation of candidates' capabilities (House of Commons Work and Pensions Committee March 2017: 30).

Difficulties in finding skilled workers may be due to job quality, wages or hiring processes. For example, employers may be unrealistic, 'putting forward unattractive job offers or display a lack of commitment to talent management' (OECD 2017: 28). The potential of some young people may be untapped where there is increased demand for skills at point of hire and 'employers use higher qualifications as a signal of capability', even where there is little or no change in the skills needed to do the job (Warhurst and Findley January 2012: 4).

The House of Lords Select Committee on Social Mobility (April 2016) has acknowledged that some employers have been changing their recruitment practices to better match young applicants' skills with jobs, but have also noted these changes tend to be concentrated in the largest employers (32). Furthermore, appropriate encouragement, opportunity and support may not be available to help young people adjust to the workplace. Workplace environments fundamentally affect how skills are put to work, but they vary in-the nature and quality of learning experiences they afford (Evans et al. 2006), the extent to which 
they are "expansive": create learning opportunities that make full use of individuals' actual capabilities and potential for development (Unwin, Felstead and Fuller 2007).

\section{Putting skills to work in the workplace environment}

\section{Findings from the Business Advisory Group discussions and interviews}

While it was beyond the study's scope to visit workplaces to research the utilisation of skills, examples drawn from the Business Advisory Group discussions and interviews pointed to the importance of supporting young adults beyond education to help them settle into the workplace and become familiar with working cultures and practices, or to start-up and grow their own business. One Group member described an employability programme initiated by his technical service company:

Modern workplaces that look like offices are set up, staffed by a recruiter, HR manager, IT support technician and business support staff. Programme participants attend one day a week to build their confidence along the journey to employment, test their behaviour in a work environment and develop technical and employability skills before working remotely in teams in different places and engaging in projects to further develop and apply soft skills.

Another Group member provided examples of practice from a not-for-profit company dedicated to addressing skills gaps in the construction and property industries. This company offers people who are disadvantaged in the labour market a combination of employability training, on-the-job experience and employment opportunities to help them settle into the workplace and progress.

The company spells out at the beginning of their selection events the realities of the job, employer requirements and expected behaviours. As soon as new recruits have been selected and commenced their pre-employment (employability) training, bespoke pastoral care, including career guidance, is offered to help them to sustain employment.

The manager has said: 'by finding the right individuals and giving them industry training specific to their particular job role, the company creates skilled workers, but our commitment doesn't stop there. We continue to work with our employees, offering emotional and practical support to ensure they are ready to start and sustain a career'.

It was felt to be important to manage expectations at the recruitment stage about the nature of the work and the working environment, with mentoring and coaching activities then helping employees engage with and learn through the workplace. Mentoring, for example, was valued 
in offering them opportunities, through learning conversations, to voice their emerging

understandings about work processes and consolidate their learning, but also to generate new knowledge and see the potential for wider application of their skills. As a CS4 programme sponsor observed: [our programme's] 'proven formula balances intensive business training with long-term mentoring to ensure young people have the strongest foundations on which to build and sustain their business'.

Young adults graduating from the Enterprise programme starting up their own business are supported by an experienced business mentor (volunteer) for two to three years. Their role is to help the young adults to achieve their goals: listen, support, highlight (the finer details), focus (help maintain an overview of business goals, measure (support with budgeting, sales conversion rates, website statistics).

From the first year of business, we had a mentoring session -3 hours every 4 weeks, to talk about where you were with things. Checking in with someone - that was very important especially when you come from a structured environment... (Entrepreneur in the Creative Industries)

The effective utilisation of skills was said to be dependent on individuals having good understanding of the business/industry context, but also on companies embracing work cultures that enable people to perform at their best. As some Group members explained:

Our industry can be a very tough environment and it is our responsibility to make sure they know what they [new recruits] are signing up for...that they fully understand what's expected of them and how to progress....

We help new recruits to become familiar with our company's culture and working practices and commit to supporting their professional development. I would ask someone going on a training course what they were going to learn, how they were going to use it and how I would notice; and then revisit these questions on their return, to make it a conscious process...

Skills shortfalls contribute to lower levels of productivity. We had to do more to empower the new intake [and] support employees to up-skill and re-skill across our working environments....

Group members acknowledged the need to have people available to support new recruits who have a good balance between industry- specific and educational expertise, and access to company resources. As one member reported: 'our recruitment and retention manager is experienced in both the industry and in supporting people who may need extra support... and we make sure training is delivered by specialists'. 


\section{Findings from the online survey}

The analysis of online survey results was limited due to the small sample (573 leavers from 3 programmes) and low response rate (c.10\%) to a breakdown of responses to individual questions. Of the 56 respondents to the survey, $64 \%$ were male ( $36 \%$ female) and all were aged over 20 at the time and had achieved a level 4 qualification or above. 89.58\% (43) were in full-time employment, three self-employment and one part-time employment, with others in Education (4), travelling (4) or doing something else. Of those in the workplace, $50 \%$ were working in the engineering and manufacturing sector and $29.17 \%$ in the construction industry, reflecting the focus of two organisations that invited them to contribute. Others included 6.25\% working in Creative and Design, $4.17 \%$ in Business and Administrative and 2.08\%, respectively, in Agriculture, Environmental and Animal Care or Legal, Finance and Accounting sectors.

The main reasons for moving into their current work were passion for this type of work (39.8\%); a step up the career ladder (22.9\%); training or opportunities for career development (18.75\%). Types of work cited by respondents mainly involved designing, project or operations management or consultancy. The majority were 'quite' or 'very satisfied' with their current work $(47.92 \% ; 37.50 \%)$, with earnings ranging from below 16k $(4.17 \%)$ to over $50 \mathrm{~K}(8.33 \%)$ a year, with half earning between $26 \mathrm{~K}$ and $31 \mathrm{~K}$.

Respondents were aware of the relevance to work of generic skills. For example, around three-quarters (78\% male and $73 \%$ female respondents) thought that in the recruitment process, their employer or contractor was looking for 'soft skills', followed by 'qualification held' and 'ambition'. Teamwork and communication, followed by problem-solving skills, were most highly rated by respondents for 'being well-prepared for work' and for 'performing well at work'. 


\section{For example}

I am part of a small team delivering approximately £20million worth of work - teamwork and leadership are very important.

Liaising with teams is crucial, even more so in consultancy work. Many will know the technicality of projects, some maybe even better than you, but if you can explain it, make them calm and guide them you will be more trusted, respected and useful.

I have to apply my problem-solving skills which I acquired during my academic training and work experience, to provide a safer environment to the everyday users, while bringing acknowledgement and profit to my company.

Resilience and creativity were also noted as important. For example:

I needed to be resilient when we've had a client come back to us multiple times with requests that have resulted in changes of direction with that project.

[Creativity] is essential because we are designing new devices... we need to resolve the challenges we come up against, we have to think creatively to come up with new concepts, ideas... and make them a reality.

The majority (87.5\%) said they had developed such skills whilst on the respective case study programmes and, in doing so, most highly rated 'learning from others' $(80.4 \%)$, followed by 'direct experience of the workplace' and 'opportunities to engage in real work tasks and problems' (62.5\% for each).

Rather than lack of skills, most responses to an open question in the online survey on 'things found difficult when starting work', concerned adjustment to the working environment. For example: 'adjusting to the social dynamics of the workplace'; 'understanding the commercial practices, business models which underpin the industry'; 'learning the culture and way of working in my new office'.

The rapid learning curve required in when starting my job (was most difficult). There wasn't much easing in...The work was less theoretical and more practical, applying codes and standards to designs and working in a market undergoing a down-turn in 2007/8 where midmanagement was scarce, so guidance was rare.' 


\section{Findings from workshop discussions and interviews with programme staff}

Putting skills to work in the programme design environment

Programme staff acknowledged the importance of taking content from professional and vocational practice, but also argued that it needed to be recontextualised to meet learners' needs and build their confidence and expertise over time. They described how they designed programmes to be developmental, with subject content, knowledge and skills related to each other to replicate workplace demands, rather than treated separately. For example:

Case study programmes CS1 and CS2 are designed specifically to encourage schools to progressively develop skills over time through a common framework for assessing, monitoring and supporting skills development during each academic year. To support their acquisition and application in combination, eight skills selected as important to performing well in the workplace, are grouped within "four critical domains": communication skills; interpersonal skills; problem solving skills; self-management skills. Each skill has descriptors at six levels setting out what learners are expected to demonstrate from five to18 years of age. CS1 supplements use of this framework with a bespoke work-readiness curriculum designed to complement teaching modules within a qualification syllabus by introducing students to skills and related concepts.

All case study programmes are designed to incorporate opportunities for the active involvement of business partners. For example, in CS1 industry partners work with the teachers to design curriculum projects covering areas of the qualification specification and plan ways for students, while on visits to workplaces, to engage with employees who are specialists in these areas and learn how to apply their skills.

As a complementary approach to subject learning, designers of an extra-curricular programme for undergraduates (CS6) take complex problems directly from industry to develop scenarios that introduce some realities of the working environment:

It's really story-telling, sometimes quite amusing, with complex implications so that students have to use their judgment in situations they haven't encountered before at university; they are required to apply several skills in combination, not only their own, but those of other team members. (Programme Manager, CS6)

Multi-disciplinary teamwork, with industry professionals judging team performance, is central to the design of this programme. 
Putting skills to work in the teaching and learning environment

To help staff in organising teaching and learning activities that promote skills development, training was said to be essential. In CS2, for example, training includes the theory of developing each skill and practical ways to develop them; videos illustrate what skills look like in a classroom setting at different levels of competence and include teachers modelling the development of these skills.

A range of teaching and learning methods and activities was described to support the development and application of skills and knowledge, where necessary taking account of specifications set by professional or examination bodies to recognise achievements. For example:

In CS4, a 4-day interactive workshop is structured to progressively build skills in specific relation to participants' personal and career interests, together with the knowledge, confidence, resilience, personal and other qualities needed to succeed in business. A mix of teaching and learning methods is used including: ice-breakers to create an appropriate learning environment; inputs from business mentors on own experiences of work to encourage identification of "transferable skills"; skills discussions, role-plays and other practical exercises to practise the application of skills, knowledge and behaviours. National Awards are offered to recognise achievements.

In CS1, the [qualification] specification is taught in a way which embeds knowledge and skill into long-term memory. Students do not complete one assignment after another, but instead return to concepts and weave through modules to ensure they can transfer and apply knowledge.

Most programme activities were reported as taking place in classroom settings, but staff described how students' experiences can be extended by bringing the world of work into the classroom: involving business partners as "knowledge brokers"; mediating links between the curriculum and work to illustrate the relevance of skills; and using authentic materials and problems.

For example:

In CS3, alumni from various occupational sectors support subject lessons and curriculum integration by co-teaching lesson content, sharing examples of practice from their workplace and bringing in materials for "hands-on" experience. Sessions can involve "learning by doing" using role-play and group problem solving tasks. 
During 12 sessions in CS2, students plan, develop and implement their own businesses to develop and demonstrate "core transferable skills". Volunteers from leading businesses support activities by giving students a chance to develop new skills while widening their understanding of the world of work.

Visits to workplaces were reported as commonly used to draw out the links between lessontime learning and work, and to provide structured activities for the deliberate practising of skills in unfamiliar settings; activities frequently involved collaborative learning or teamwork. For example:

In CS1, students worked in groups on lesson-time projects which included organising two events at their college. They then went on a trip to a company to enhance teamwork and presentation skills developed in the classroom: 'learn how to apply these skills in a real-world context and bring their learning to life'(Programme Manager). Expert advice was provided by four volunteers from the company.

We did our recruitment project in a UK company. This helped with our communication and improved our skills... they gave us a project on how we could market their buildings to their clients... We had to present our ideas back to a board of employees... (Student from CS1)

The programme manager of CS6 events explained how learners are put into situations of uncertainty when engaging in authentic tasks that not only involve the application of instrumental skills, but also metacognitive skills such as arranging, planning, and organisation. For example:

Scenarios require application of several skills when, for example, students are evaluating the finances, the energy performance and the aesthetic quality of a construction balanced against the time and cost to develop it. This requires bringing in all the different skills and abilities of team members, with individuals having to communicate the value of their expertise. "Situational knowledge" is developed as they begin to see how their skill sets and what they have learnt applies to the context in which they are going to work. They also develop "tacit knowledge" of the workplace, what it means to be professional, which fits in with what is required by professional organisations. 'Rather than being taught new knowledge, it is more about learning how to apply knowledge and recognising the value of what they have learnt'. (Manager CS6)

In reflecting the "complexity of reality" such experience was believed to help learners understand the relevance of the skills they are using, but also develop their vocational identity.

Teaching and learning to support learner recontextualisation of skills requires learners themselves to identify and understand the relevance of skills. 
Programme staff recognised the importance of learners having adequate opportunities to

reflect on their skills and practice, but also the need for encouragement and support from others

to draw out their learning and consider their further development. For example:

CS3 introduces students to the idea of "transferable skills" through sessions that involve alumni in answering questions about how they use skills at work. Alumni, acting in a coaching role, then help students draw out their own skills. During a reflection task, students are asked to put skills cards in order of importance in getting a job and then identify subjects in which they are learning these skills, and those they need to improve.

From the start, the case study organisations take time to ensure learners understand the nature

of skills and their relevance to personal and career development. For example:

Our teachers focus on how they can break quite large concepts into small digestible chunks and build in time each day for deliberate practice to ensure that the component parts of using this skill move into long-term memory. This is conducted both formally through the work readiness curriculum and informally through the culture of the classroom where students are required to practise skills daily such as teamwork, problem-solving and presentation skills. (CS1 Programme Manager)

In CS5, undergraduates are offered an opportunity to design their own professional development programme. There is the potential to develop "career adaptability skill" in requiring individuals to look ahead to where they think their careers are going, explore own knowledge, skills and abilities, weigh up options and start planning for the acquisition of skills they will need to achieve their potential when, following graduation, they move into leadership positions within a UK industry and pursue their aspirations.

Opportunities are provided for learners to self-assess, review, discuss and reflect on skills

they are developing, with feedback to inform further learning. For example:

In CS4, learners are encouraged to explore how they learn best, record and reflect on their learning, using questions to aid reflection and feedback from mentors. At the start, a selfassessment form is introduced to explain its purpose and make sure they understand it. At a mid-point stage, a member of staff facilitates skills discussions, encouraging the young person to reflect on how they think their skills are developing, and whether their initial assessment was realistic. At the end, when deciding whether, or not, to start a business, they go back to the form and rank where they are now. A panel of volunteers with experience of starting a business provides feedback on business plans.

To prepare learners for the realities of the workplace, most of the case study programmes include practical assignments that require learners to progressively take responsibility for solving work-related problems. 
For example:

In CS3 learners work with alumni on practical assignments that involve them in addressing workplace problems drawn, for example, from HR, marketing or finance departments. They work in groups role-playing a range of stakeholders.

In CS2, students engage in a combination of lesson-time projects, challenge days and workplace visits. Each assignment is designed to progressively build on students' skills, with challenges involving working in teams to tackle problems such as setting up and running a production line or turning around a failing firm.

A mix of activities enables participants to learn how to apply their skills to suit tasks and problems in different situations, some of which are unfamiliar and offer less support from teachers. As one applicant for an award to support business start-up put it: 'I had learnt before how to put together a budget and a proposal, so it wasn't a new experience for me. It was more about having to prove you could do it in a real situation that was new. It was self-led'.

\section{Discussion}

Findings from our study suggest that employability is more than a one-off preparation for work and requires more than that which can be taught in Education. Once in the workplace, young adults need support to become familiar with its culture, norms and practices, develop, adapt and learn new skills in order to meet changing demands of the labour market, and create and seize opportunities for career progression. It may be tempting to see employability in terms of a list of skills, but context matters. For example, while recognising the role of "soft skills" in the recruitment process and performing well in the workplace, survey respondents found adjusting to the physical and social aspects of the working environment most difficult.

The case studies illustrate how students can learn how to cross boundaries between education and work by engaging with people from business and industry in classroom activities that use authentic materials and replicate some of the demands of the workplace. However, for young recruits to make their knowledge and skills applicable to different situations, tasks and activities over time depends as much, if not more, upon the extent to 
which the workplace is "expansive", offers opportunities for development, as upon experiences, knowledge and skills developed while in Education.

It is known from previous research (e.g. Oates, August 1992; Savickas, 1997; Evans et al. 2006; Fettes, 2012) that work requires a holistic approach, and integrated capabilities: the ability of individuals to 'put it all together' in performance and apply "career adaptability skill" in navigating career progression and managing change. It is not simply a matter of "skills transfer", a term which implies that skills learnt in one context can be automatically redeployed in another virtually unchanged. The metaphor of "transfer" does not help in being dogged by assumptions about gaps between general subject-based learning and the assumed nature of practice at work and a rather static notion of skills. It says little about how skills can be contextualised and recontextualised in moving between different environments, the metacognitive skills, higher-order thinking ability, that enables individuals to know when and how to adapt their skills or learn new skills, or the personal attributes that facilitate their ability to do so.

At the programme design stage, skills can be mapped against activities to ensure coverage of those relevant to the subject matter and contextualise the skills for learners, but this alone is insufficient. To be able to recontextualise skills for themselves in moving between education and work, and between jobs, individuals need to become flexible, selfregulating learners. Putting skills to work is not a one-off event, but 'a continuous, contextually-embedded, transformative process'. It requires progressive development of capabilities supported by multi-faceted partnerships, with the expectation of the active involvement of the learner in, for example, adopting an inquiring approach, using work tasks as test-beds, seeing adults from the workplace as sources of information and advice, recognising use of skills and articulating their learning and development. 
The case studies have shown that effective practice does exist in preparing young people for work. The respective programmes have exhibited many of the features of "powerful learning environments" (as defined by de Bruijn and Leeman. 2011) and understanding of the four modes of recontextualisation (as described by Evans, Guile and Harris. 2018): content; pedagogical; workplace; and learner. For example, programmes have been designed and facilitated to provide opportunities for the gradual transfer of responsibility for the contextualisation of skills from teacher to learner, to enable learners to become increasingly self-regulating, and learn from their mistakes, in progressively moving from carefully controlled learning environments to those that reflect the complexities (both physical and social) of real-life work.

Key features of such practice include: making skills and their relevance to work explicit to learners through, for example, skills discussions; "learning by doing", problem-solving and collaborative work; co-teaching, coaching and mentoring by business partners; carefully-structured opportunities to practise the application of skills in a variety of activities and situations; opportunities for self-assessment, review and reflection, with feedback to inform development. However, most of the programmes have been reliant on expertise and support external to the school or university. Not all young people have access to such provision.

Examples provided by the business advisory group have shown that firms can adopt appropriate recruitment practices and provide on-going support for new recruits to enable them to perform at their best, but this practice is also far from widespread. Companies are under continual productivity pressures and it is a challenge to even the most committed company to maintain a high level of involvement and engagement. It requires skilled learning facilitators, time, resources and understanding of the mutually beneficial relationship between employee development and business performance. 
Although the literature review, supported by findings from further research by Kashefpakdel with Newton and Clark (November 2018), indicates that there is a fair degree of agreement about what types of skill and qualities are needed and well-rehearsed arguments as to why these are important to the UK's economy and individuals, less attention has been given to how skills can be best developed, recognised and utilised in the workplace.

As Unwin, Felstead and Fuller (June 2007) suggest, once learning is viewed holistically as a complex, contextualised process, there can be more meaningful exploration of how skills and knowledge can be developed, adapted, transformed and shared to support young adults in utilising their skills. However, to successfully manage the 'chain of recontextualisation' from the design of programme content, through teaching and learning and into the workplace, is very demanding. It requires co-ordinated, collaborative partnerships between education providers and employers, with shared understanding of each partner's traditions and commitments, and learners who are active and motivated to learn. In scaling up programmes that support skills development over a realistic timescale, greater ownership is needed by a wider constituency, including policy makers, and better understanding of the interrelationships between skills supply, demand and utilisation. To inform these partnerships, more research is required building, for example, on the case study approaches described by Evans, Guile and Harris; Anderson and Warhurst; Green et al; and Keep ${ }^{5}$.

\footnotetext{
${ }^{5}$ Evans, K., Guile, D. and Harris, J. October 2009. Putting Knowledge to Work: The Exemplars. UCL Institute of Education http://discovery.ucl.ac.uk/1527268/. Anderson, R. and Warhurst, C. 2012. Lost in Translation? Skills Policy and the Shift to Skill Ecosystems. Chapter 9. In Complex New World: Translating New Economic Thinking into Public Policy edited by Dolphin, T. and D. Nash. IPPR, pp. 109-120. Green, A., Hogarth, T., Thom, G., MacLeod, K., Warhurst, C., Willis R. and Mackay, S. 2017. Local Skills Case Study (Department for Education Research Report 673). Keep, E. August 2016. Improving Skills Utilisation in the UK - Some Reflections on What, Who and How? SKOPE Research Paper No. 123. Oxford: Oxford University, SKOPE.
} 


\section{Acknowledgements}

The authors thank the Commercial Education Trust (CET) for sponsoring the study and the CET projects that volunteered to contribute. Also, Education \& Employers and the Edge Foundation for providing an opportunity to present and discuss findings at the $5^{\text {th }}$ International Conference on Employer Engagement, 5 and 6 July 2018 in London.

\section{Declaration of interest statement}

No financial interest or benefit has arisen from the direct applications of the research.

\section{References}

Akkerman, S. F. and Bakker, A. 2012. Crossing Boundaries Between School and Work During Apprenticeships. Vocations and Learning (5):153-173

Bound, H., Evans, K., Sadik, S. and Karmel, A. 2018. How Non-permanent Workers Learn and Develop. Abingdon: Routledge

Confederation of British Industry and Pearson. July 2016. The Right Combination. CBI/Pearson Skills Survey 2016. London: CBI

Construction Industry Training Board. June 2015. The Future of Jobs and Skills in the UK Construction Industry Executive Summary. London: CITB

De Bruijn, E. and Leeman, Y. 2011. Authentic and Self-directed Learning in Vocational Education: Challenges to Vocational Educators. Teaching and Teacher Education, Vol. 27 (4), pp. 694-702. Development Economics. January 2015. The Value of Soft Skills to the UK Economy. London: McDonald's UK

Ebenehi, A.S., Rashid, A.M. and Bakar, A.R. Predictors of Career Adaptability Skill among Higher Education Students in Nigeria. International Journal for Research in Vocational Education and Training. Vol. 3. (3). December 2016

Evans, K., Hodkinson, P., Rainbird, H. and Unwin, L. (2006) Improving Workplace Learning. Abingdon: Routledge

Evans, K., Guile, D. and Harris, J. October 2008. Putting Knowledge to Work: Integrating Workbased Knowledge and Subject-based Knowledge in Intermediate Qualifications and Workforce Upskilling. Teaching and Learning Research Briefing, Number 60. T.L.R.P./E.S.R.C.

Evans, K., Guile, D., Harris, J. and Allan, H. 2010. Putting Knowledge to Work: A New Approach. Nurse Education Today. Vol 30 (3), pp 245-251

Fettes, T. 2012. Generic Skills. Chapter 7. In Work-related Teaching and Learning. Edited by Stanley, J. and Huddleston, P. Abingdon: Routledge

HM Treasury. 2015. Fixing the Foundations: Creating a More Prosperous Nation. London: HMSO House of Commons Work and Pensions Committee. March 2017. Employment Opportunities for Young People. Ninth Report of Session 2016-17

House of Lords Select Committee on Social Mobility. April 2016. Overlooked and Left Behind: Improving the Transition from School to Work for the Majority of Young People. Report of Session 2015-16. London: The Stationery Office

Kashefpakdel E. T. and C. Percy. 2016. Career Education that Works: An Economic Analysis Using the British Cohort Study. Journal of Education and Work. Doi: 10.1080/13639080.2016.1177636 Kashefpakdel E. T., Newton, O. and Clark, J. November 2018. Joint Dialogue: How are Schools Developing Real Employability Skills? London: Education and Employers

Koen, J., Ute-Christine Klehe- and A. M. E. Van Vianen. 2012. Training Career Adaptability to Facilitate a Successful School-to-work Transition. Journal of Vocational Behaviour 81, 395-408 Mann, A. and Huddleston, P. 2016. Schools and the Twenty First Century Labour Market: Perspectives on Structural Change. British Journal of Guidance and Counselling, 45:2, 208-218 
Mann, A., Kashefpakdel, E.T., Rehill , J. and Huddleston, P. January 2017. Contemporary

Transitions: Young Britons Reflect on Life After School and College. London: Education and Employers

Mann, A., Rehill, J. and Kashefpakde, E.T. January 2018. Insights from International Evidence for

Effective Practice and Future Research. London: Education and Employers Research/Education

Endowment Foundation

Oates, T. August 1992. Core Skills and Transfer: Aiming High. Innovations in Education and

Training International, 29(3): 227-239

Organisation for Economic Co-operation and Development. 2013. Innovative Learning Environments.

Paris: OECD

Organisation for Economic Co-operation and Development. 2017. Better Use of Skills in the

Workplace. Why It Matters for Productivity and Local Jobs. Paris: OECD

Purcell, K., Elias, P., Green, A., Mizen, P., Simms, M., Whiteside, N., Wilson, D., Robertson, A. and

Tzanakou, C. September 2017. Present Tense, Future Imperfect? Young people's pathways into work.

E.S.R.C.

Quintini, G., Martin, J.P. and Martin, S. January 2007. The Changing Nature of the School-to-work

Transition Process in OECD Countries. Discussion Paper No. 2582. Bonn: Institute for the Study of Labor (IZA)

Savickas, M. L.1997. Adaptability: An Integrative Construct for Life Span, Life-space Theory.

Career Development Quarterly, 45, 247-259

Schoon, I. and Lyons-Amos, M. 2016. Diverse Pathways in Becoming an Adult: The Role of

Structure, Agency and Context. Research in Social Stratification and Mobility. 10 (3): 11-20. Doi:

10.1016/j.rssm.2016.02

Universities UK. August 2018. Solving Future Skills Challenges. London: Universities UK

Unwin, L., Felstead, A. and Fuller, A. June 2007. Learning at work: towards more 'expansive' opportunities. Paper prepared for the NIACE Commission of Inquiry into The Future for Lifelong Learning

Warhurst, C. and Findley, P. January 2012. More Effective Skills Utilisation: Shifting the Terrain of Skills Policy in Scotland. SKOPE Research Paper No. 107. SKOPE

Youth Employment UK. 2017. The Youth Employment UK Employability Review. Kettering: Youth Employment UK 